\title{
A Literature Review on People-Centered Care and Nursing Practice in Primary Health Care Setting
}

\author{
Adepeju. M. Lateef ${ }^{1} \&$ Euphemia. M. Mhlongo ${ }^{1}$ \\ ${ }^{1}$ Department of Nursing, School of Nursing and Public Health, University of KwaZulu-Natal, Howard College, \\ Durban, 4001, South Africa \\ Correspondence: Adepeju M. Lateef, University of KwaZulu-Natal, School of Nursing and Public Health, Howard \\ College, Desmond Clarence Building 5th Floor, Durban, 4001, South Africa. Tel: 27-632-134-579. E-mail: \\ princessadepejuu@gmail.com
}

Received: September 9, 2019 Accepted: October 22, 2019 Online Published: January 30, 2020

doi:10.5539/gjhs.v12n2p23

URL: https://doi.org/10.5539/gjhs.v12n2p23

\begin{abstract}
Background: With increased research, the concept of people-centered care is advancing, and it remains an important concept in the health sector. Despite reported evidence of significant benefits, this concept is poorly utilized by professional nurses. The principle has not been demonstrated and absorbed at primary health care levels.
\end{abstract}

Aim: The aim of this study is to present review of literature on people-centered care (PCC) in nursing and its practice in primary health care setting.

Methods: Searching for this study is conducted through electronic databases in which the following databases were searched: PubMed, Google Scholar, Science Direct, EMBASE, and CINAHL, MEDLINE, Health sources: Nursing/Academic edition, PsycINFO, Education source, Academic search complete, and psychARTICLE from EBSCOhost platform. The Joanna Briggs Institute Reviewers' Manual 2015 methodology framework was used as a guide to conduct the search strategy. Furthermore, in this review study, both peer reviewed articles and grey studies on people centered care were reviewed.

Result: The findings of this research review outlined the evidence, practicability and acceptability of nursing care with people-centered care concept in the primary health care centers. Considering that nurses play a vital role in the health sector, it is possible to use people-centered care in Primary Health Care settings. However, there are many difficulties and obstacles identified such as: absence of nursing fraternity training and growth, absence of clear educational advancement resulting from change in accreditation, small number of nurses at the organizational level of health care organizations, and reduced global health care organization assistance.

Discussion: The results from this review highlighted evidence of the relationship between quality healthcare deliveries of nurses with people-centered care concept in primary healthcare centers. Nurses' role in delivering PCC and gauging their knowledge and understanding is becoming imperative and crucial. In primary health care environments, nurses play a significant role in understanding a patient's culture of quality and efficient health care.

Keywords: people-centered care, nurses, nursing care, practice, primary health care setting, and health sector

\section{Introduction}

People-Centered Care (PCC) is not a new concept in the health sector because it was first introduced in 1987 in recognition of the role of patients in personal health by the Children's Care Association (Abraham \& Moretz, 2012; Choi \& Kim, 2014). Despite the existence of PCC principles since 1950 (C. R. Rogers, 1952), they have not been demonstrated and absorbed at the primary health care level. It may be integrated and implemented by individual nursing units, but resistance to wider implementation is still very high (Dingeman, Mitchell, Meyer, \& Curley, 2007).

World attention has been drawn to PCC (Frampton et al., 2008; Williams, 2007). PCC has appealed to both developed and developing nations as it improves the literacy of inclusion in health care (Nuño, Coleman, Bengoa, \& Sauto, 2012). As a consequence, several beneficial results such as enhanced physician consultation time, enhanced patient mental equilibrium, and adherence to therapy requirements and schedules have been achieved (Mirzaei et al., 2013; Pulvirenti, McMillan, \& Lawn, 2014; Stewart, 2013). 
PCC was developed with the sole purpose of enhancing health care services planning, assessment and delivery. It is based on mutual benefit principles for all healthcare partners and participants (Leape et al., 2009). PCC provides a number of benefits such as dignity, respect, data sharing, cooperation and involvement to patients and health care providers (Carman et al., 2013; Johnson et al., 2008). Therefore, in any health care system or organization, PCC targets all age groups (Abraham \& Moretz, 2012). In addition, the application of PCC results in patient empowerment and satisfaction, decrease in symptom severity, enhanced use of health care facilities and resources by patients, and reduced health costs due to decentralized care (Holmström \& Röing, 2010). The following primary concepts are therefore adopted by PCC (Brooker, 2003; Ferguson, 2007):

- Caring and putting value on the patient

- Handling and treating patients according to their individual needs

- Taking care of patients holistically (i.e. mentally, socially, physically and spiritually)

\subsection{Research Question}

What are the documented evidences of nursing practice and people centered care in primary health care setting?

\subsection{Background and Significant}

While PCC is challenging in its application and cost, its tremendous results are recognized by organisations. These results not only benefit patients, but also nurses working in health care institutions (Ahmann, Abraham, \& Johnson, 2010; Conway et al., 2006). Nurses work in units and are better positioned in clinics and other health care institutions to implement and champion PCC (Evans \& Pablos-Méndez, 2016; Kamei et al., 2017). As such, it should not go without mentioning that bringing about change is crucial to the main role that nurses play in organizational culture. Consequently, nurses need to know and research the requirements, dislikes and likes of their clients, their values, capabilities, their nature of assistance and their needs for assistance in relation to their historical background (Thompson, Heath, \& Mills, 2013). This attitude of collaboration will allow nurses and other health professionals to assist patients make informed decisions about their health direction without prejudice (D. Brown, McWilliam, \& Ward-Griffin, 2006; Hudon, Fortin, Haggerty, Lambert, \& Poitras, 2011; Sidani et al., 2014). Other researchers, however, have found a contrary thinking to PCC, arguing that it is a vague and poorly conceptualized principle (DiGioia III, Lorenz, Greenhouse, Bertoty, \& Rocks, 2010; Laschinger, Heather, Gilbert, Lesley, \& Leslie, 2010; Smith, Dewar, Pullin, \& Tocher, 2010).

In order to understand and acknowledge PCC, the following features should be observed (Kim Manley, Sanders, Cardiff, \& Webster, 2011):

- Focus on understanding patient values, beliefs, aspirations, health and social needs.

- Patients should be permitted to make important choices and decisions on options provided by the health care professionals. In other words, patient independence and autonomy should always be respected.

- Evidence of shared roles in decision making without control from the primary health care givers or organizations over the patient. In other words, reduced control over the patient specific health care choice to meet their social preferences and other needs.

- Providing individual patients with tailor-made information to enable them make decisions based on evidence. This enables patients to comprehend and interpret complicated medical concepts and technical information. Furthermore, this enables patients know the implications of their decisions while at the same time drawing support from health care professionals.

- Support for patients, irrespective of their health care choices. Health care professionals should be able to advocate patient preferences as indicated by the patients. In other words, health care providers should respect choices made by patients.

- Evaluation and self-examination of the care and services provided to patients by collecting and addressing feedback concerns from patients and their family health care givers.

Therefore, it is essential for PCC health care providers to have the knowledge and skills required to implement PCC (Jackson, 2011). Other characteristics should include the connection between patient primary health care providers to experience and reap the advantages of high-quality health care (Innes, 2006; Kim Manley, Titchen, \& Hardy, 2009).

\subsection{Definition of PCC, Modern Concepts and Its Characteristics}

PCC's definition owes its roots to the holistic care moving from the traditional model oriented towards disease 
(Epstein, 2000; Epstein, Fiscella, Lesser, \& Stange, 2010). However, its popularity did not start to grow until the 1970s. While its definition varies depending on environments and perspectives, four primary views and configurations are used to define it:

- The public policy perspective

- The economic perspective

- The clinical perspective

- The patient perspective

Nevertheless, PCC is defined as the coming together of health caregivers, patients and family care providers to guarantee that patients want, needs and preferences are respected to assist patients in their own care (International Alliance of Patients' Organizations, 2007). (Booth, Murray, \& Tyers, 2004; Wensing, Grol, Weel, \& Felling, 1998). However, in defining PCC, each of these views is crucial. It is therefore essential to remember that there has not been a patient definition, but study has only recognized its features (Gensichen et al., 2005).

Historically, patients have been given paternalistic care by health care providers in clinical settings (Teutsch, 2003). Hence, clinical perspective is a traditional approach that focuses on providing patient focus or preference care (Robinson, Callister, Berry, \& Dearing, 2008). PCC is therefore concept characterized by responsiveness to the needs and preferences of patients. This is achieved by guiding informed choices for patients through interactions, providing information, and sharing decisions (A. Rogers, Kennedy, Nelson, \& Robinson, 2005). In other words, health care providers are responsible for understanding the patient as a person compared to a cluster of diseases (Epstein, 2000). As a result, PCC provides patients with medical care from a point of view, values involvement, compassionate presence, offering mental and physical requirements as assistance for the patient (McCormack \& McCance, 2006).

Modern PCC concepts emerge from the limitations of the biomedical model, also known as the traditional or clinical model perspective (Mead \& Bower, 2000; Shaller, 2007). PCC holistically acknowledges the patient with mental, psychological and social requirements by putting the patient at the centre (Flarey, 1995; Pence, 1997). Currently, PCC is conceptualized into two main approaches:

- Systems model-This model consists of a hierarchy of activities and builds that create a patient-centered environment. This model emphasizes satisfying primary health care needs of individualized patients. By arranging caregivers and all stakeholders around patients ' requirements, this model is accomplished (Ponte et al., 2003; Shaller, 2007). Figures 1 and 2 show the PCC system model's organizational structure.

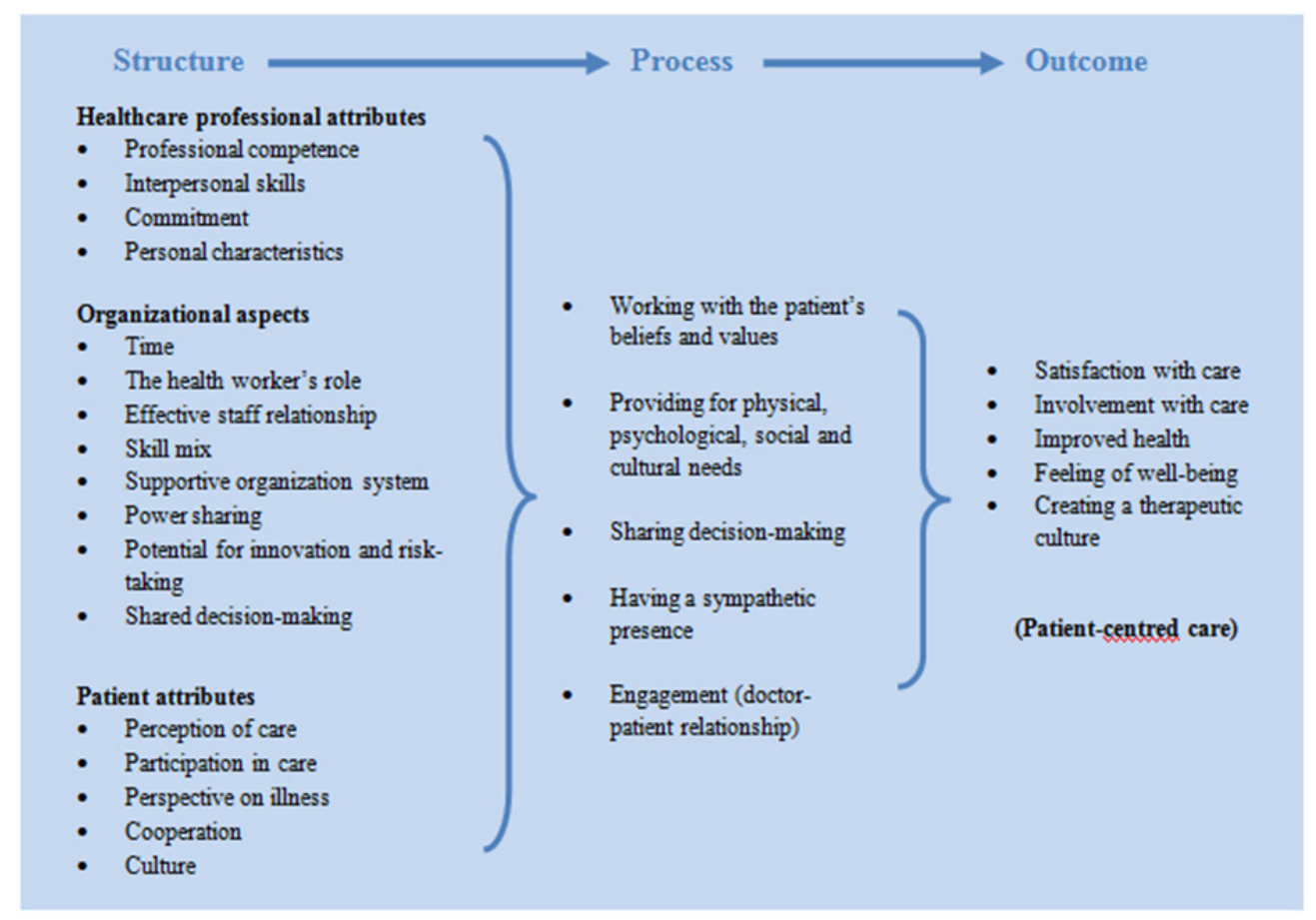

Figure 1. A system theory of patient-centred care (McCormack \& McCance, 2006) 

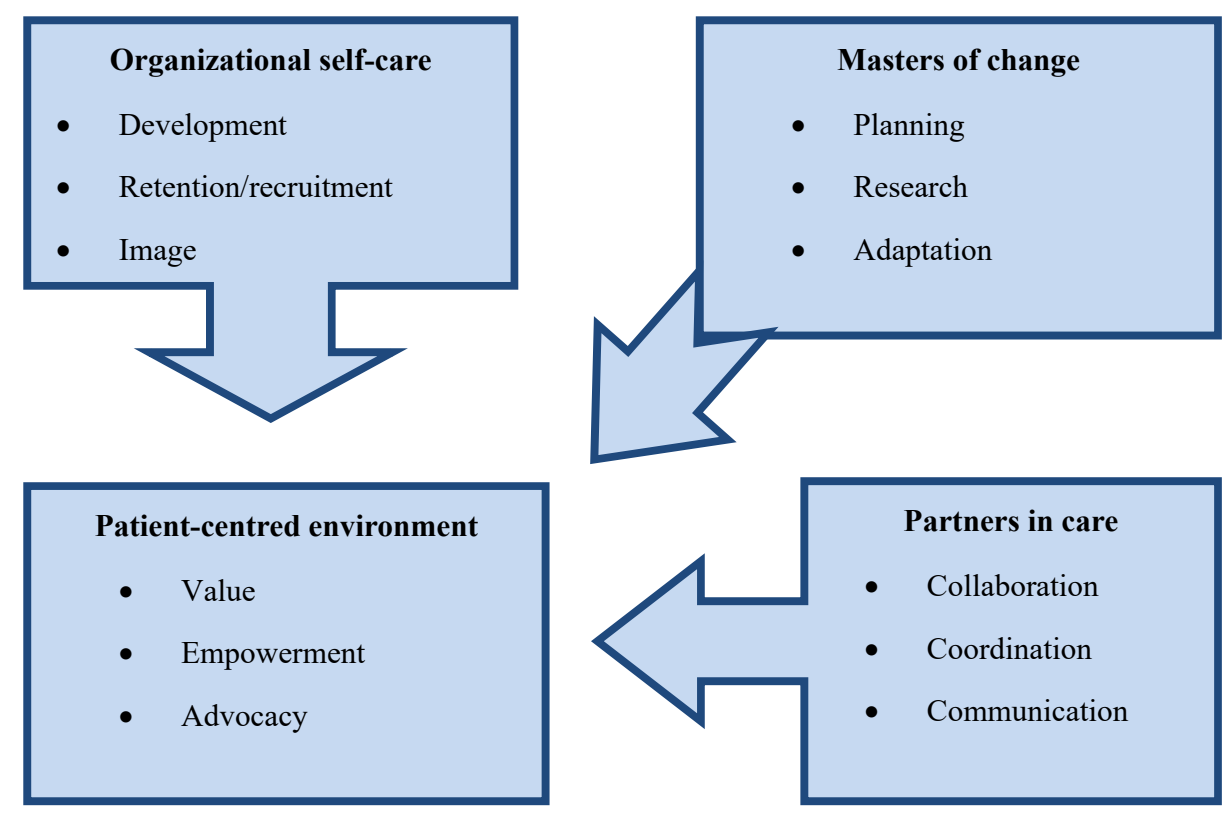

Figure 2. A systems model approach to PCC (Flarey, 1995)

- $\quad$ Process model-The hierarchy strategy of the process model adopts and cooperates patient views. It includes and describes a range of activities such as consideration of patient beliefs, values, needs expressed by patients, integration of coordination and care, patient education and communication on treatment and care, and physical comfort provision. In relation to these operations, the process model also includes: emotional support, participation of family care providers in patient management and decision-making transition and patient health care continuity measures as they pass through different phases of rehabilitation (D. Brown et al., 2006). Table 1 illustrates a PCC process model.

\subsection{The Impact of PCC on Health Care as a Leading Approach Towards Improved Health Care Service}

Health care has evolved from a paternalistic approach to knowing what is best for patients by doctors, nurses and other health care providers to an all-inclusive approach where the patient takes a centre stage. It is the medical practitioners who instructed and prescribed treatment in the paternalistic care scheme, but without input from patients or family care (Delaney, 2018). This traditional approach has often been widely criticized as its focus has been on the decisions of medical practitioners. It gave them the power and exclusion of patients who were supposed to be the essence of their very existence as experts around whom health care was based (Rodriguez-Osorio \& Dominguez-Cherit, 2008). This permitted the health care giver to usurp all decision-making powers with little regard for any of the values, needs or preferences of patients (Buchanan, 2008). Instead of the patients ' family traditions or values, paternalism focused on the disease and its management (Epstein et al., 2010). 
Table 1. PCC process model

\begin{tabular}{|c|c|}
\hline Dimensions & Process \\
\hline $\begin{array}{l}\text { Respect for persons values, preferences and } \\
\text { expressed needs }\end{array}$ & $\begin{array}{l}\text { Accepting patient as a person, involving patients in care decision-making, } \\
\text { listening and considering patients' needs and maintaining confidentiality to } \\
\text { protect patients' information. }\end{array}$ \\
\hline Coordination and integration of care & $\begin{array}{l}\text { Working in multidisciplinary approach, coordinating and integrating } \\
\text { clinical care, involving patient and family in planning, decision-making and } \\
\text { quality improvement processes at organization level. }\end{array}$ \\
\hline Information, communication and education & $\begin{array}{l}\text { Providing accurate and understandable information about treatment, care } \\
\text { and interventions, listening actively to the patient and family, and provide } \\
\text { therapeutic touching and talking when necessary. }\end{array}$ \\
\hline Physical comfort & $\begin{array}{l}\text { Promoting comfortable and supportive hospital environment, providing } \\
\text { timely, tailored and expert managegment of symptoms, and providing basic } \\
\text { healthcare that supports and maintains normal body functions. }\end{array}$ \\
\hline $\begin{array}{l}\text { Emotional support and allivation of fear and } \\
\text { anxiety }\end{array}$ & $\begin{array}{l}\text { Listening to patient with undivided attention, providing clear, timely and } \\
\text { meaningful information regarding the illness, and caring with empathy }\end{array}$ \\
\hline Involvement of family and friends & $\begin{array}{l}\text { Providing with enough information regarding the patient's illness, } \\
\text { respecting and acknowledging the family and friends' support in patient } \\
\text { care, and providing supportive environment. }\end{array}$ \\
\hline Transaition and continuity of care & $\begin{array}{l}\text { Providing clear information and education on dangers sign to watch, what } \\
\text { to do and how to handle medications and preventive measures, and } \\
\text { referring patient to appropriate level of health system with clear } \\
\text { instructions. }\end{array}$ \\
\hline
\end{tabular}

However, health caregivers and institutions in today's world recognize both the importance of PCC in health care delivery (Department of Health, 2008; Picker Institute, 1987, 1999; World Health Organisation, 2007). If it has to have an effect, PCC's primary objective is to provide a working relationship between health caregivers, patients, and families to provide quality health care services. It is important to note, however, that PCC does not have a universally accepted definition, its concept embodies holistic attitudes while considering each individual patient as a biopsychosocial and physiological whole (Saleem, J. Alharbi, Olsson, Ekman, \& Carlström, 2014). Holistic viewing of patients ensures that their individual needs are not neglected but satisfied with respect and responsiveness in making informed choices (Washington \& Lipstein, 2011). In other words, PCC is a paradigm shift to concepts of health care that are grounded on values and personal preferences that are based on health care partnership foundations. The Picker Institute first launched PCC to mainstream health care in 1993. This institute performed a study that highlighted the need to respect the requirements and preferences and values of patients, psycho-physiological comfort, communication, support and coordinated care that includes family and friends of patients (Delaney, 2018; Jose, Jimmy, Al-Mamari, Al-Hadrami, \& Al-Zadjali, 2015).

Since this strategy has flexibility and is tailored to individual requirements, values and preferences, PCC improves the quality of health care supplied and its outcomes (Australian Commission on Safety and Quality in Health Care, 2010; Luxford, Safran, \& Delbanco, 2011). A paternalistic approach jeopardizes the patient's right to self-determination and autonomy because there is no parity in the patient nurse relationship. When compromised, these two principles support patients and decrease autonomy as the process of healing is postponed while improving patient reliance (Entwistle, Carter, Cribb, \& McCaffery, 2010; Mackenzie, 2008). PCC provides the following impacts when implemented by health care providers in health care institutions:

- Shared collaboration and decision-making by promoting patient participation. This is through listening and valuing the patient's health care management opinions and personal preference (Leplege et al., 2007).

- In particular, PCC enhances concordance between health care providers and patients with respect to the treatment plan (Roumie et al., 2011; Thompson et al., 2013).

- PCC enhances health care results and patient satisfaction with their corresponding health care institutions or service providers (Bertakis \& Azari, 2011; Ekman et al., 2012).

- There is considerable advantage for patients as they are helped to make informed choices and even when they 
make contrary choices to medical advice, they are assured of assistance from health care providers (Bertakis \& Azari, 2011; Delaney, 2018).

- PCC helps to decrease the patient's need for specialized care $(\mathrm{p}<0.0209)$ and hospitalization $(\mathrm{p}<0.0027)$ (Bertakis \& Azari, 2011).

- $\quad$ PCC ensures medical compliance and adherence to the treatment regime (RR3.19, 95 percent, CI 1.44, 16.3) in chronic disease patients (Roumie et al., 2011).

- PCC improves self-perception in patients and decreases stress while improving empowerment of patients. This is important for patients with diabetes a debilitating chronic disease (Hermans et al., 2013; Shortell, Gillies, Anderson, Mitchell, \& Morgan, 1993).

\subsection{The Health Care System Management and Reform Policy - A Reflection on Nigeria}

Health systems are large and complex entities in any country, but under constant change. Thus, the global reform agenda is a dominant factor regardless of the results of the health care system. Health care system reform simply means a sustained, purposeful and fundamental reorganization to bring about change (Marušič \& Rupel, 2016). There is, however, consensus that reform is a change process involving the health sector's "WHAT," "WHO," and "HOW." It is possible to divide health reform into two primary fields, partial and global reform. The former includes operational changes, growth and incremental issues on a daily basis. The partial reforms are designed to address specific concerns, such as infant mortality and ageing. On the other hand, the entire system is shaped by global reforms which are intended and implemented for significant changes in society, such as demographic, political, social, economic and technological changes. It is important to note, however, that efficiency or radical reform depends on the configuration of the governance and political structure, both of which are influenced by contextual circumstances, such as the state economy.

The development of the Nigerian Primary Health Care system in line with the Alma-Ata dates back to 1978. This was a continuation of the Third National Development Plan of 1975-1980, which established the philosophy of Primary Health Care (PHC) philosophy (National Primary Health Care Development Agency, 2013). In 1986, Nigeria's federal government selected 52 Local Government Areas (LGAs) as PHC service models. These facilities were paired with colleges of health and schools of health technology. A fresh policy based on the values of PHC and the Alma-Ata declaration was launched in 1988 with its main components being the establishment of the Nigerian health care directorate within the Ministry of Health. Its primary role was to formulate, develop and implement the national PHC system (Adeyemo, 2005).

In 1992, a national health care agency was set up by the government with zonal offices in Enugu, Ibadan, Kaduna, and Bauchi (World Health Organization, 2017). This essentially split Nigeria into health zones to facilitate the roll-out, execution, oversight and coordination of effective programs (Federal Ministry of Health, 2010). Another restructuring was ordered that created more departments like the PHC and, as stated previously, the development of the NPHCDA. A number of federal government programs to revitalize the PHC were implemented by this agency. For example, the Midwives Services Scheme, Maternal and Child Health Subsidy Investment Programs (Onokerhoraye et al., 2014). The Bamako Initiative Policy Program was launched by the federal government of Nigeria in 2003-2007. This program is a component of the 2003-2007 National Economic Empowerment and Development Strategy. This policy was a review of existing policies and plans for public health while creating new ones. It also established collaboration of state entities in PHC with the private sector and stakeholders (Federal Ministry of Health, 2012).

Nigeria's federal government proposed to reposition the Nigerian public health sector with seven specific goals alongside the public health reform strategy for improved service delivery that included (World Health Organization, 2017):

- Improved stewardship role of the FGN.

- Strengthening the national health system and management structures.

- Reduction of the national burden of disease.

- Improved national health resources management.

- Improved access to quality Primary Health Care

- Promotion of effective partnership, collaboration and coordination between the public and private sectors.

- Improved awareness and community involvement in important matters of public health and decision making.

Other notable reform policy initiatives that have been significant in the FGN include: 
- Merging of the NPHCDA with the National Health Bill.

- Development of health-related MDG framework in Nigeria.

- Revision of the NHP and the national immunization programme.

- Development of a national plan of action for delivery of the ward minimum health care package.

- Launch of the National Health Insurance Scheme and revitalization of the Federal Ministry of Health.

- Development of integrated maternal, new born and child health strategy.

- Development of sub-sectoral policies, such as the Public Private Partnership, human resource development for health, health financing, health research and equipment, HIV and AIDS response, the National Drug Policy, and the National Malaria Strategic Plan.

Because of the above reforms since 2010-2015, the FGN developed a 5-year National Strategic Health Development Plan. This plan contained eight strategic areas of priority that were decided and developed on a need basis by the department of health and other federal health institutions (Federal Ministry of Health, 2010). Table 2 shows the flow of policy initiatives and reforms in Nigeria related to PHC (World Health Organization, 2017).

Table 2. A flow of policy initiative and reforms in Nigeria related to PHC (World Health Organization, 2017)

\begin{tabular}{ll}
\hline Year & Reform in relation to Primary Health Care in Nigeria \\
\hline $1975-1980$ & Basic Health Service Scheme \\
1986 & Adoption of 52 Local Government Areas as model for PHC \\
1987 & Adoption of Bamako Initiative programme \\
1988 & Launching of National Health Policy \\
$1999-$ & Set up National PHC Development Agency (NPHCDA) \\
$1999-2004$ & Law enabling National Health Insurance Scheme signed in 1999 Amended in 2004 \\
2004 & Merger of NPHCDA AND Programme on immunization Revised National Health Policy \\
$2004-2007$ & Implementation of the health sector reform programme \\
2009 & Development of a 5-year National Strategic Health Development Plan (2010-2015) \\
2014 & National Health Act with provision for Basic Healthcare Provision Fund to strengthen PHC \\
\hline
\end{tabular}

\subsection{The Nursing Practice of PCC in Primary Health Care Settings}

PCC is highly valued in primary health care settings as it addresses the needs of each patient (Bogale, Beharu, Tesfaye, \& Belay, 2017). PCC addressed these individual needs by concentrating on the patient rather than the practice of managing the disease (Constand, MacDermid, Dal Bello-Haas, \& Law, 2014; Rathert, Wyrwich, \& Boren, 2013). People-centered care helps nursing practitioners to respect individual patient preferences, needs, and values and respond appropriately. This ensures that a patient is guided to make clinical decisions independently. Modern nursing practices therefore require nurses to consider cultural traditions, religious beliefs, private preferences, values, family situations, social conditions and lifestyles of the patients (Lusk \& Fater, 2013; McCance, Slater, \& McCormack, 2009).

Currently, PCC has limited data on employee perception and research priority except in the United States (Balbale, Turcios, \& LaVela, 2015; Coyne, Murphy, Costello, O’Neill, \& Donnellan, 2013; Esmaeili, Cheraghi, \& Salsali, 2014; Gillespie, Florin, \& Gillam, 2004; Taylor \& Groene, 2015). As the research community continues to examine PCC, policies and other initiatives are implemented by the health care system (Epstein et al., 2010; Scholl, Zill, Härter, \& Dirmaier, 2014). However, the concept's complexity contributes to the challenge of implementing PCC in nursing practice to a greater extent (McCance, McCormack, \& Dewing, 2011).

The definitions of PCC are vague and blurred at the organisational stage where nurses work (Smith-Stoner, 2011). Furthermore, feasibility and effectiveness are in doubt (Rangachari, Bhat, \& Seol, 2011). As such, the literature surveyed is uncertain about how PCC impacts outcomes (Lusk \& Fater, 2013). Care outcomes in PCC are essential and are the primary components of the approach. For instance in a study by (Maxson, Derby, Wrobleski, \& Foss, 2012), the authors reported increased patient satisfaction with nursing bed reports, while enhancing safety in nursing practice. Furthermore, drug mistakes were reduced and patient nursing relationships enhanced (Merav \& 
Hochman, 2017). Studies also revealed a $26 \%$ increase in the proportion of detected mistakes (Licata et al., 2013) and a decrease in mistakes associated with shift changes in some surveys (Cronin-Waelde \& Sbardella, 2013).

Nursing education in the nursing fraternity is an important element in the implementation of PCC, in particular training and skill development. Nursing development should be equipped with tools through education and training programs to identify specific patient needs for shared decision-making (Merav \& Hochman, 2017). Communication (Smith-Stoner, 2011) is one of the most critical skills that nurses should be taught besides inclusion of content in quality care in their curriculum. These skills should not be theoretical but practical, however, by using modern simulation tools to evaluate the student's ability in PCC practice (Onge \& Parnell, 2015). This has been proven and reported widely through research, for instance in (R. Brown, Feller, \& Benedict, 2010; Girdley, Johnsen, \& Kwekkeboom, 2009; Jenkins, Blake, Brandy-Webb, \& Ashe, 2011).

PCC has been shown to improve the quality of care and patient satisfaction when included in nursing practice, a key factor in a patient's rehabilitation. Policymakers and implementers around the globe have been pushing for the implementation of PCC, a pillar of health care (Moore et al., 2017; Saleem et al., 2014). PCC has been one of the priority areas of health sector reforms in Nigeria since 2004 (National Primary Health Care Development Agency, 2013). PCC has been given top priority by the FGN Ministry of Health in its efforts to improve quality and equity in the delivery of health care systems (Abraham \& Moretz, 2012; Epstein et al., 2010). Despite all these merits, however, PCC still faces monumental challenges throughout Nigeria in its implementation because its integration into the nursing care and practice is patchy and inconsistent. While PCC is recognized by the government as a main dimension in PHC, it is still poorly implemented in nursing practice. There are three major contributing factors in Nigeria to this scenario (Bogale et al., 2017):

- The performance of providers

- The structural and organizational features of the health system

- Broader socio-economic environment under which nursing practice is done

\subsection{An Evaluation of Job Satisfaction, Personnel Training, Work, Ethnicity and PCC}

One of the recent developments owing to the implementation of patient surveys is job satisfaction. These studies provide feedback on the quality of service provided to the public by health care providers, managers and policy makers (West, Barron, \& Reeves, 2005). These surveys show the importance of hearing and responding to the experiences of patients in order to provide physical comfort, emotional support and respect for their preferences (Jenkinson, Coulter, Bruster, Richards, \& Chandola, 2002). However, little has been done after the results of these surveys. Furthermore, there has been no response from the policy makers to engage health care institutions constructively on how to respond to complaints from patients.

Nursing staff provide organisational information, management and resources to enhance the quality and experience of patients at the hospitals. However, it is not evident how hospitals use this feedback particularly in fields that are essential for patients and nurses to enhance their work satisfaction (Lu, Barriball, Zhang, \& While, 2012). For instance, any questionnaires ask nurses about time, instruments and training accessibility in the literature surveyed. These are fundamental instruments or resources that nurses need in order to provide patients with quality care (Picker Institute, 1999). In other words, the questionnaires of nursing employees should provide information on their capacity to provide care in certain important fields such as (Gerteis, 1993; Peschel \& Peschel, 1994):

- Respect for patients' values, preferences and expressed needs

- Coordination and integration care

- Information, communication and education

- Physical comfort

- Emotional support and alleviation of fear and anxiety

- Involvement of family and friends

- Transition and continuity

Due to the acute shortage of nursing staff, interest in their quality of work has increased in Nigeria where budgetary constraints are limiting the empowerment and training of new nursing staff. As such (den Boer, Nieboer, \& Cramm, 2017) notes that the shift from uniform procedures to collaboration and customization of working methods in the provision of quality health care is necessary. The well-being of nurses and their job satisfaction has seen a greater attention due to the workload and work related stress. For instance, in a recent study in the 
Netherlands $80 \%$ of the nurses reported to have experienced work related stress and pressure due to the care needs assessment (V\&VN, 2015). Other researchers such as (Khamisa, Oldenburg, Peltzer, \& Ilic, 2015) have also shown a connection to work related stress and job satisfaction. Job satisfaction is therefore a significant variable considering its connection with job changes and work related stress (Geiger-Brown et al., 2004; Toh, Ang, \& Devi, 2012).

However, the findings of (den Boer et al., 2017; Gittell, Douglass, Ancona, Backman, \& Parrot, 2011) report distinct results that is in favour of well-being relative to job satisfaction in collaboration and co-creation. These results have shown that co-creation is a social human aspect, particularly the quality of working relationships (Nieboer, Lindenberg, Boomsma, \& Bruggen, 2005). Consequently, job satisfaction tends to be based on practical elements such as wages, work climate, work preparation and skills development (Geiger-Brown et al., 2004; Lu, While, \& Barriball, 2005; Stuart, Jarvis, \& Daniel, 2008; Toh et al., 2012). These obviously defends the stance of these elements are related to PCC and its effective execution. Which clearly defends the position of these aspects are linked to PCC and its successful implementation.

\subsection{People Centered Care Challenges in Nigeria}

It is important to recognize the fact that each day and practice is a challenge, sometimes successful, chaotic and unpredictable (Dewing, 2008; K Manley, McCormack, \& Wilson, 2008; McCormack, Dewing, \& Mccance, 2011). It should also be remembered that caring is not a straight forward affair as it may appear (Theodosius, 2013). By recognizing that each person is different with preferences and personality, putting these factors in the heart of nursing care is essential (Borbasi, Galvin, Adams, Todres, \& Farrelly, 2013; Hemingway, Scammell, \& Heaslip, 2012; Todres, Galvin, \& Holloway, 2009). However it should be understood also that competing priorities can in many ways intervene and prevent quality and fully humanized care (Riding, Glendening, \& Heaslip, 2017).

Therefore, there must be some practice contexts which affect the implementation of PCC among these key factors which bring contextual challenge include:

- Work place culture- wards and departments (Kim Manley et al., 2011).

- Learning culture- abilities to tolerate tension, support and enable innovation, learning from mistakes, maximizing individual potentials, understanding team and system processes (Falender \& Shafranske, 2014; Kaye, 2005; Kim Manley et al., 2009).

- The physical environment which include cleanliness and clean hospital (Arneill \& Frasca-Beaulieu, 2003).

In other words, it should be a continuous process of development within the nursing profession while developing a PCC culture. This shows important development components in nursing practice that focus on assisting caregivers know the context of their work and the features of their environment that hinder the delivery of quality PCC health care (Kim Manley, McCormack, Wilson, \& Thoms, 2008). Thus, nurses are motivated to be active learners in practice (Dewing, 2008; McCormack et al., 2011). Since this is an in-depth learning that integrates numerous learning techniques, it should be driven by personal and emotional attachment of practice and patient experience (McCormack et al., 2011).

This enables nurses to be open in engagement while learning from experiences or seeing and doing critical reflection from personal experiences. The recognition of these variables as a customer with legitimate expectations and concerns will lead to the general reception and satisfaction of the health care service every time patients visit a health care facility. The perception of the quality of health care provided is based solely on subjective attitudes, but not on satisfaction (Adebayo, Adesina, Ahaji, \& Hussein, 2014). The single most essential component of nursing practice is therefore good communication between patients and caregivers. This is due to the rapid and clear identification of the problems, while at the same time defining expectations that create confidence between health care providers and patients (Iliyasu, Abubakar, Abubakar, Lawan, \& Gajida, 2010; Olakunde, 2012). Other factor will include cost of health care services, technical quality of HCPs and the income levels of the patients.

Patient income levels affect their satisfaction with health care service owing to the increased cost of health care services. This is against a backdrop of a high poverty index of $63 \%$ (United Nations Development Programme, 2013). As such, this type of expenditure affects the family income negatively resulting into low health care satisfaction (Naidu, 2009; Olakunde, 2012). Patient satisfaction with health care providers is used by insures, providers and researchers due to tits intrinsic value as an indicator of health care consumer preference and secondly due to the ease of measurement (Edlund, Young, Kung, Sherbourne, \& Wells, 2003). The main challenges identified in Nigeria through literature review, include the following (Adeleke, 2010; Adisa, 2015; Bening, 2016; Makata, Ilo, \& Agbapuonwu, 2016): 
- Lack of clear academic progression paths resulting from changes in certification based solely on employment quantification. This lacks a clear role in the development of skills by simply carrying out a mass promotion of certification into National Diplomas without requiring further training or skills growth. For instance, in Nigeria health care workers have been slow to embrace University education as compared to the other health care professionals.

- Lack of provision of adequate financial resources. Transformation to PCC requires time, effort and availability of financial muscle and reimbursement during the transitional period.

- Lack of opportunities for training and development in the nursing fraternity. This has adversely affected understanding and led to poor use of current concepts in the process of modern nursing practice, such as evidence-based practices, best practices, advanced nursing practice, PCC, etc. These practices are designed to improve nursing practice in Nigeria's quality of care.

- There is a general belief that since women are more oriented to primary care, they are best suited for nursing care. This has resulted to an acute marginalization in nursing as most nurses are women.

- Lack of full implementation of PCC functions. It is important to look at and examine the impact of line item costs that are related to a full implementation of the PCC approaches.

- Low numbers of health care staff at the managerial level make tier voices drown in the health care system. It thus becomes difficult to introduce and implement new ideas, techniques and strategies in nursing care. This contributes to negative growth of nursing care and poor quality of health care services.

- The creation of nursing professional rights advocacy organisations such as the National Association of Nigerian Nurses and Midwives (NANNM) tended to concentrate on welfare relative to development and training, maintenance of nursing practice and standards, and monitoring nursing education. As such, these organizations do not promote career development however essential it may be.

- Lack of government incentives such as promotions, good remuneration packages and the recruitment of new nursing staff to cope with shortages. This is primarily due to budget limitations in Nigeria following the World Bank's prescribed structural adjustment programs to reduce recurring spending. This has reduced the quality and standards of health care provided in public health institutions, in addition to lowering nurses' morale.

- Diminishing international organisation support for public sector health care and nursing education in the public sector. This has been due to the demand for political and economic accountability since 2008, taking into account the global economic meltdown. Recent developments, however, indicate increased demands attached to social changes such as acceptance of gay and lesbian legislation before aid can be granted by international organizations.

\section{Methods}

Although this study is a narrative review, which is a part of a $\mathrm{PhD}$ research project. The Joanna Briggs Institute Reviewers' Manual 2015 of Population Concept Context (PCC) was adopted to determine the eligibility criteria of the search. According to the manual, Population Concept Context is recommended structured for reviews (Joanna Briggs Institute, 2015). Population in this study are the nursing caring and professional nurse, and registered nurses. Concept, which represent the intervention is people-centred care, person-centered care, client-centered care, patient-centered care, patient-oriented care, and patient focused care, and Context is the Primary Health Care setting (Joanna Briggs Institute, 2015). 
Table 1. Population Concept Context (PCC) framework for determination of eligibility of the search

\begin{tabular}{ll}
\hline Criteria & Determinants \\
\hline Population & Nursing care, and professional nurses. Nurses are professional healthcare providers in healthcare system \\
\hline \multirow{2}{*}{ Concept } & $\begin{array}{l}\text { People-centred care. } \\
\text { It is a holistic quality approach to healthcare service delivery at the point of care. }\end{array}$ \\
\hline \multirow{2}{*}{ Context } & Primary healthcare settings globally. \\
& Primary Health Care is the grass root of healthcare system. \\
\hline
\end{tabular}

The following electronic databases were searched, PubMed, Google Scholar, Science Direct, EMBASE, and CINAHL, MEDLINE, Health sources: Nursing/Academic edition, PsycINFO, Education source, Academic search complete, and psychARTICLE from EBSCOhost platform. In addition, grey literature and citations from the reference list of articles were searched as well. This approach is important to identify the current gap in knowledge in the field of interest.

\section{Discussion}

The concept of PCC promotes the quality of health care delivery in the health sector significantly. Since nurses constitute $80 \%$ of the workforce in the Primary Health Care systems (Hughes, 2008), it will be important for them to adopt and promote PCC as health care givers. This will impact positively on the quality of health care provided to the public (World Health Organization, 2015). The focus of this study review is on nurses because they are the main custodian of Primary Health Care centers (Jill Maben \& Peter Griffiths, 2008) and form the foundation in the healthcare system, which is of a great concern to WHO.

The current situation of PHC setting in Nigeria is critical as identified in this study. However, it has potential to transform and become better despite the prevailing challenges. Some of these critical challenges include: lack of training and development opportunities for the nurses, lack of clear academic progression that arise from changes in certification, low number of nurses at managerial levels and community health care institutions, reduced support from international organizations, and cultural differences based on individual ethnocentrism for integrating PCC. In addition, the degree of knowledge is tied with nurses' utilization of PCC which is connected to quality healthcare service delivery.

The objective of this study is to present evidence of PCC application through nursing practice in Nigeria and its challenges in the health care system. Although the implementation of PCC in Nigeria has not been fully achieved, the findings of this study review show that the PCC approach to health care delivery is effective in providing high-quality health care services to achieve universal health coverage for all (Flagg, 2015; World Health Organization, 2015). The identified challenges will further guide areas of healthcare improvement and nursing practice in the Nigerian PHC system.

\section{Conclusion}

It is essential to note that in most government and private health care facilities, few studies have been performed to evaluate PCC in nursing practice in Nigeria. Therefore, further study and evaluation of such a significant area of health service delivery will be the subject of our study with an aim of addressing the aforementioned challenges.

\section{Acknowledgements}

The authors are solely responsible for the work and acknowledge the support provided by the School of Nursing and Public Health, University of KwaZulu-Natal. Research reported in this publication was supported by the Fogarty International Center (FIC), NIH Common Fund, Office of Strategic Coordination, Office of the Director (OD/OSC/CF/NIH), Office of AIDS Research, Office of the Director (OAR/NIH), National Institute of Mental Health (NIMH/NIH) of the National Institutes of Health under Award Number D43TW010131. The content is solely the responsibility of the authors and does not necessarily represent the official views of the National Institutes of Health.

\section{Completing Interest Statement}

The authors declare there are no potential conflicts of interest.

\section{References}

Abraham, M., \& Moretz, J. G. (2012). Implementing patient-and family-centered Care: Part I-understanding the 
challenges. Pediatric Nursing, 38(1), 44-48.

Adebayo, E. T., Adesina, B. A., Ahaji, L. E., \& Hussein, N. A. (2014). Patient assessment of the quality of dental care services in a Nigerian hospital. Journal of Hospital Administration, 3(6), 20-28. http://dx.doi.org/10.5430/jha.v3n6p20

Adeleke, A. O. (2010). The challenges of best practices and standards in nursing in Nigeria Inaugural lecture series: Igbenedion University, Okada.

Adeyemo, D. (2005). Local government and health care delivery in Nigeria: A case study. Journal of Human Ecology, 18(2), 149-160. https://doi.org/10.1080/09709274.2005.11905822

Adisa, T. (2015). The inter-relationship between work-life balance and organisational culture: an empirical study of Nigerian health sector. (Doctor of Philosophy), Brunel University London. Retrieved from http://bura.brunel.ac.uk/handle/2438/11561

Ahmann, E., Abraham, M., \& Johnson, B. (2010). Institute for Patient-and Family-Centered Care. Emergency Medicine, 15, 109-111.

Arneill, B., \& Frasca-Beaulieu, K. (2003). Healing environments: Architecture and design conducive to health. Putting Patients First, 163-190.

Australian Commission on Safety and Quality in Health Care. (2010). Patient-Centred Care: Improving Quality and Safety by Focusing Care on Patients and Consumers. Canberra: Biotext.

Balbale, S. N., Turcios, S., \& LaVela, S. L. (2015). Health care employee perceptions of patient-centered care. Qualitative Health Research, 25(3), 417-425. https://doi.org/10.1177/1049732314553011

Bening, A. (2016). Application of Nursing Process and its Influence on the quality of Nursing Care in Wa Regional Hospital. (Master of Nursing degree), University of Cape Coast. Retrieved from http://hdl.handle.net/123456789/3054

Bertakis, K. D., \& Azari, R. (2011). Determinants and outcomes of patient-centered care. Patient education and counseling, 85(1), 46-52. https://doi.org/10.1016/j.pec.2010.08.001

Bogale, T., Beharu, M., Tesfaye, T., \& Belay, Y. (2017). Scope of Patient Centered Care Practice in Public Hospitals of Benishangul Gumuze Regional State, South West Ethiopia. Quality in Primary Care, 26(1), 31-37.

Booth, A., Murray, A., \& Tyers, A. (2004). The direct brow lift: efficacy, complications, and patient satisfaction. British journal of ophthalmology, 88(5), 688-691. http://dx.doi.org/10.1136/bjo.2003.019232

Borbasi, S., Galvin, K. T., Adams, T., Todres, L., \& Farrelly, B. (2013). Demonstration of the usefulness of a theoretical framework for humanising care with reference to a residential aged care service in Australia. Journal of Clinical Nursing, 22(5-6), 881-889. https://doi.org/10.1111/j.1365-2702.2012.04256.x

Brooker, D. (2003). What is person-centred care in dementia? Reviews in clinical gerontology, 13(3), 215-222. https://doi.org/10.1017/S095925980400108X

Brown, D., McWilliam, C., \& Ward-Griffin, C. (2006). Client-centred empowering partnering in nursing. Journal of Advanced Nursing, 53(2), 160-168. https://doi.org/10.1111/j.1365-2648.2006.03711.x

Brown, R., Feller, L., \& Benedict, L. (2010). Reframing nursing education: The Quality and Safety Education for Nurses initiative. Teaching and Learning in Nursing, 5(3), 115-118. https://doi.org/10.1016/j.teln.2010.02.005

Buchanan, D. R. (2008). Autonomy, paternalism, and justice: Ethical priorities in public health. American journal of public health, 98(1), 15-21.

Carman, K. L., Dardess, P., Maurer, M., Sofaer, S., Adams, K., Bechtel, C., \& Sweeney, J. (2013). Patient and family engagement: A framework for understanding the elements and developing interventions and policies. Health Affairs, 32(2), 223-231. https://doi.org/10.1377/hlthaff.2012.1133

Choi, M., \& Kim, J. (2014). Associated Factors in Pediatric Nurse Parent Partnership. Child Health Nursing Research, 20(3), 176-184. https://doi.org/10.4094/chnr.2014.20.3.176

Constand, M. K., MacDermid, J. C., Dal Bello-Haas, V., \& Law, M. (2014). Scoping review of patient-centered care approaches in healthcare. BMC health services research, 14(271), 1-9.

Conway, J., Johnson, B., Edgman-Levitan, S., Schlucter, J., Ford, D., Sodomka, P., \& Simmons, L. (2006). 
Institute For Patient-And Family-Centered Care. Retrieved 29th August, 2019, from https://www.ipfcc.org/resources/Roadmap.pdf

Coyne, I., Murphy, M., Costello, T., O’Neill, C., \& Donnellan, C. (2013). A survey of nurses' practices and perceptions of family-centered care in Ireland. Journal of family nursing, 19(4), 469-488. https://doi.org/10.1177/1074840713508224

Cronin-Waelde, D., \& Sbardella, S. (2013). Patientcentered transfer process for patients admitted through the ED boosts satisfaction, improves safety. ED Management, 24(2), 17-20.

Delaney, L. J. (2018). Patient-centred care as an approach to improving health care in Australia. Collegian, 25(1), 119-123. https://doi.org/10.1016/j.colegn.2017.02.005

den Boer, J., Nieboer, A. P., \& Cramm, J. M. (2017). A cross-sectional study investigating patient-centred care, cocreation of care, well-being and job satisfaction among nurses. Journal of Nursing Management, 25(7), 577-584. https://doi.org/10.1111/jonm. 12496

Department of Health. (2008). High Quality Care for All - NHS Next Stage Review Final Report. London: Department of Health.

Dewing, J. (2008). Becoming and being active learners and creating active learning workplaces: The value of active learning in practice development. International practice development in nursing and healthcare, 273-294.

DiGioia III, A., Lorenz, H., Greenhouse, P. K., Bertoty, D. A., \& Rocks, S. D. (2010). A patient-centered model to improve metrics without cost increase: viewing all care through the eyes of patients and families. Journal of Nursing Administration, 40(12), 540-546. 10.1097/NNA.0b013e3181fc1

Dingeman, R. S., Mitchell, E. A., Meyer, E. C., \& Curley, M. A. (2007). Parent presence during complex invasive procedures and cardiopulmonary resuscitation: A systematic review of the literature. Pediatrics, 120(4), $842-854$.

Edlund, M. J., Young, A. S., Kung, F. Y., Sherbourne, C. D., \& Wells, K. B. (2003). Does satisfaction reflect the technical quality of mental health care? Health services research, 38(2), 631-645. https://doi.org/10.1111/1475-6773.00137

Ekman, B., Bachrach-Lindström, M., Lindström, T., Wahlberg, J., Blomgren, J., \& Arnqvist, H. J. (2012). A randomized, double-blind, crossover study comparing two-and four-dose hydrocortisone regimen with regard to quality of life, cortisol and ACTH profiles in patients with primary adrenal insufficiency. Clinical endocrinology, 77(1), 18-25. https://doi.org/10.1111/j.1365-2265.2012.04352.x

Entwistle, V. A., Carter, S. M., Cribb, A., \& McCaffery, K. (2010). Supporting patient autonomy: The importance of clinician-patient relationships. Journal of general internal medicine, 25(7), 741-745.

Epstein, R. M. (2000). The science of patient-centered care. Journal of Family Practice, 49(9), 805-810.

Epstein, R. M., Fiscella, K., Lesser, C. S., \& Stange, K. C. (2010). Why the nation needs a policy push on patient-centered health care. Health Affairs, 29(8), 1489-1495.

Esmaeili, M., Cheraghi, M. A., \& Salsali, M. (2014). Critical care nurses' understanding of the concept of patient-centered care in Iran: A qualitative study. Holistic nursing practice, 28(1), 31-37. 10.1097/HNP.0000000000000002

Evans, T., \& Pablos-Méndez, A. (2016). Shaping of a new era for health financing. The Lancet, 387(10037), 2482-2484. https://doi.org/10.1016/S0140-6736(16)30238-0

Falender, C. A., \& Shafranske, E. P. (2014). Clinical supervision: The state of the art. Journal of Clinical Psychology, 70(11), 1030-1041. https://doi.org/10.1002/jclp.22124

Federal Ministry of Health. (2010). National Strategic Health Development Plan. Abuja, Nigeria: Federal Ministry of Health.

Federal Ministry of Health. (2012). Revised National Health Policy. Retrieved 05/06/2019, from Federal Republic of Nigeria http://cheld.org/wp-content/uploads/2012/04/Nigeria-Revised-National-Health-Policy-2004.pdf

Ferguson, J. (2007). Person-Centred Dementia Care: Making services better. London and Philadephia: Jessica Kingsley Publishers.

Flagg, A. J. (2015). The role of patient-centered care in nursing. Nursing Clinics, 50(1), 75-86. 
Flarey, D. L. (1995). Redesigning nursing care delivery: Transforming our future: Lippincott.

Frampton, S., Guastello, S., Brady, C., Hale, M., Horowitz, S. M., Smith, S. B., \& Stone, S. (2008). Patient-centered care improvement guide.

Geiger-Brown, J., Trinkoff, A. M., Nielsen, K., Lirtmunlikaporn, S., Brady, B., \& Vasquez, E. I. (2004). Nurses' perception of their work environment, health, and well-being: a qualitative perspective. Aaohn Journal, 52(1), $16-22$.

Gensichen, J., Torge, M., Peitz, M., Wendt-Hermainski, H., Beyer, M., Rosemann, T., . . Gerlach, F. M. (2005). Case management for the treatment of patients with major depression in general practices-rationale, design and conduct of a cluster randomized controlled trial-PRoMPT (Primary care Monitoring for depressive Patient's Trial) [ISRCTN663860866]-Study protocol. BMC public health, 5(1), 101. doi:10.1186/1471-2458-5-101

Gerteis, M. (1993). Through the patient's eyes: understanding and promoting patient-centered care.

Gillespie, R., Florin, D., \& Gillam, S. (2004). How is patient-centred care understood by the clinical, managerial and lay stakeholders responsible for promoting this agenda? Health Expectations, 7(2), 142-148. https://doi.org/10.1111/j.1369-7625.2004.00264.x

Girdley, D., Johnsen, C., \& Kwekkeboom, K. (2009). Facilitating a culture of safety and patient-centered care through use of a clinical assessment tool in undergraduate nursing education. Journal of Nursing Education, 48(12), 702-705. https://doi.org/10.3928/01484834-20091113-05

Gittell, J. H., Douglass, A., Ancona, D., Backman, E., \& Parrot, K. (2011). Relational Leadership: New Developments in Theory and Practice. Waltham, MA: Brandeis University. (White paper).

Hemingway, A., Scammell, J., \& Heaslip, V. (2012). Humanising nursing care: A theoretical model. Nursing times, 108(40), 26-27.

Hermans, M. P., Elisaf, M., Michel, G., Muls, E., Nobels, F., Vandenberghe, H., \& Brotons, C. (2013). Benchmarking is associated with improved quality of care in type 2 diabetes: The optimise randomized, controlled trial. Diabetes Care, 36(11), 3388-3395. https://doi.org/10.2337/dc12-1853

Holmström, I., \& Röing, M. (2010). The relation between patient-centeredness and patient empowerment: A discussion on concepts. Patient education and counseling, 79(2), 167-172. https://doi.org/10.1016/j.pec.2009.08.008

Hudon, C., Fortin, M., Haggerty, J. L., Lambert, M., \& Poitras, M.-E. (2011). Measuring patients' perceptions of patient-centered care: A systematic review of tools for family medicine. The Annals of Family Medicine, 9(2), $155-164$.

Hughes, R. (2008). Patient Safety and Quality: An Evidence-Based Handbook for Nurses (Vol. 3): Agency for Healthcare Research and Quality Rockville, MD.

Iliyasu, Z., Abubakar, I., Abubakar, S., Lawan, U., \& Gajida, A. (2010). Patients' satisfaction with services obtained from Aminu Kano Teaching Hospital, Kano, Northern Nigeria. Nigerian Journal of Clinical Practice, 13(4), 371-378.

Innes, A., Macpherson, S., McCabe, L., \& Joseph. (2006). Promoting Person-Centred Care at the Front Line. New York, UK: Rowntree Foundation.

International Alliance of Patients' Organizations. (2007). What is Patient-centred care? London: IAPO.

Jackson, A., \& Irwin, W. (2011). Dignity, humanity and equality: Principles of Nursing Practice A. Nursing Standard, 25(28), 35-37. https://doi.org/10.7748/ns2011.03.25.28.35.c8396

Jenkins, S., Blake, J., Brandy-Webb, P., \& Ashe, W. (2011). Teaching patient safety in simulated learning experiences. Nurse educator, 36(3), 112-117. https://doi.org/10.1097/NNE.0b013e31821611dc

Jenkinson, C., Coulter, A., Bruster, S., Richards, N., \& Chandola, T. (2002). Patients' experiences and satisfaction with health care: A esults of a questionnaire study of specific aspects of care. BMJ Quality \& Safety, 11(4), 335-339. https://doi.org/10.1136/QHC.11.4.335

Jill Maben, \& Peter Griffiths. (2008). Nurses in Society: Starting the Debate. London: National Nursing Research Unity.

Joanna Briggs Institute. (2015). The Joanna Briggs Institute Reviewers' Manual 2015: Methodology for JBI 
Scoping Reviews. The University of Adelaide, Australia: The Joanna Briggs Institute.

Johnson, B., Abraham, M., Conway, J., Simmons, L., Edgman-Levitan, S., Sodomka, P., \& Ford, D. (2008). Partnering with patients and families to design a patient-and family-centered health care system. Institute for Patient-and Family-Centered Care and Institute for Healthcare Improvement.

Jose, J., Jimmy, B., Al-Mamari, M. N., Al-Hadrami, T. S., \& Al-Zadjali, H. M. (2015). Knowledge, beliefs and behaviours regarding the adverse effects of medicines in an Omani population: Cross-sectional survey. Sultan Qaboos University Medical Journal, 15(2), 250-256.

Kamei, T., Takahashi, K., Omori, J., Arimori, N., Hishinuma, M., Asahara, K., . . Tashiro, J. (2017). Toward Advanced Nursing Practice along with People-Centered Care Partnership Model for Sustainable Universal Health Coverage and Universal Access to Health. Revista latino-americana de enfermagem, 25, 1-10. http://dx.doi.org/10.1590/1518-8345.1657.2839

Kaye, B. (2005). Build a culture of development. Leadership excellence, 22(3), 18.

Khamisa, N., Oldenburg, B., Peltzer, K., \& Ilic, D. (2015). Work related stress, burnout, job satisfaction and general health of nurses. International Journal of Environmental Research Public Health, 12(1), 652-666. https://doi.org/10.3390/ijerph120100652

Laschinger, S., Heather, K., Gilbert, S., Lesley, M., \& Leslie, K. (2010). Towards a comprehensive theory of nurse/patient empowerment: Applying Kanter's empowerment theory to patient care. Journal of Nursing Management, 18(1), 4-13. https://doi.org/10.1111/j.1365-2834.2009.01046.x

Leape, L., Berwick, D., Clancy, C., Conway, J., Gluck, P., Guest, J., . . . O’Neill, P. (2009). Transforming healthcare: A safety imperative. BMJ Quality \& Safety, 18(6), 424-428. https://doi.org/10.1136/qshc.2009.036954

Leplege, A., Gzil, F., Cammelli, M., Lefeve, C., Pachoud, B., \& Ville, I. (2007). Person-centredness: Conceptual and historical perspectives. Disability and rehabilitation, 29(20-21), 1555-1565. https://doi.org/10.1080/09638280701618661

Licata, J., Aneja, R. K., Kyper, C., Spencer, T., Tharp, M., Scott, M., . . Pasek, T. A. (2013). A foundation for patient safety: Phase I implementation of interdisciplinary bedside rounds in the pediatric intensive care unit. Critical care nurse, 33(3), 89-91. https://doi.org/10.4037/ccn2013280

Lu, H., Barriball, K. L., Zhang, X., \& While, A. E. (2012). Job satisfaction among hospital nurses revisited: A systematic review. International journal of nursing studies, 49(8), 1017-1038. https://doi.org/10.1016/j.ijnurstu.2011.11.009

Lu, H., While, A. E., \& Barriball, K. L. (2005). Job satisfaction among nurses: A literature review. International journal of nursing studies, 42(2), 211-227. https://doi.org/10.1016/j.ijnurstu.2004.09.003

Lusk, J. M., \& Fater, K. (2013). A concept analysis of patient-centered care. Paper presented at the Nursing Forum.

Luxford, K., Safran, D. G., \& Delbanco, T. (2011). Promoting patient-centered care: A qualitative study of facilitators and barriers in healthcare organizations with a reputation for improving the patient experience. International Journal for Quality in Health Care, 23(5), 510-515. https://doi.org/10.1093/intqhe/mzr024

Mackenzie, C. (2008). Relational autonomy, normative authority and perfectionism. Journal of Social Philosophy, 39(4), 512-533. https://doi.org/10.1111/j.1467-9833.2008.00440.x

Makata, N., Ilo, C., \& Agbapuonwu, N. (2016). Multi-linear Pathways in Nursing Education in Nigeria: A Professional Albatross. International Journal of Nursing Education, 8(3), 57-62.

Manley, K., McCormack, B., \& Wilson, V. (2008). Practice development in nursing: international perspectives: Blackwell, Oxford.

Manley, K., McCormack, B., Wilson, V., \& Thoms, D. (2008). 18. The Future Contribution of Practice Development in a Changing Healthcare Context. International practice development in nursing and healthcare, 379-398. https://doi.org/10.1002/9781444319491

Manley, K., Sanders, K., Cardiff, S., \& Webster, J. (2011). Effective workplace culture: The attributes, enabling factors and consequences of a new concept. International Practice Development Journal, 1(2), 1-29.

Manley, K., Titchen, A., \& Hardy, S. (2009). Work-based learning in the context of contemporary health care education and practice: A concept analysis. Practice Development in Health Care, 8(2), 87-127. https://doi.org/10.1002/pdh.284 
Marušič, D., \& Rupel, V. P. (2016). Health care reforms. Slovenian Journal of Public Health, 55(3), 225-227. https://doi.org/10.1515/sjph-2016-0028

Maxson, P. M., Derby, K. M., Wrobleski, D. M., \& Foss, D. M. (2012). Bedside nurse-to-nurse handoff promotes patient safety. Medsurg Nursing, 21(3), 140-147.

McCance, T., McCormack, B., \& Dewing, J. (2011). An exploration of person-centredness in practice. The Online Journal of Issues in Nursing, 16(2), 1-9. http://dx.doi.org/10.3912/OJIN.Vol16No02Man01

McCance, T., Slater, P., \& McCormack, B. (2009). Using the caring dimensions inventory as an indicator of

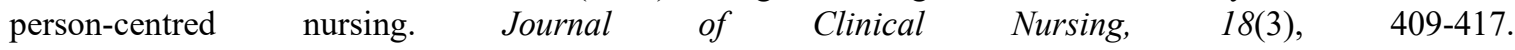
https://doi.org/10.1111/j.1365-2702.2008.02466.x

McCormack, B., Dewing, J., \& Mccance, T. (2011). Developing person-centred care: Addressing contextual challenges through practice development. The Online Journal of Issue in Nursing, 16(2), 1-11.

McCormack, B., \& McCance, T. V. (2006). Development of a framework for person-centred nursing. Journal of Advanced Nursing, 56(5), 472-479. https://doi.org/10.1111/j.1365-2648.2006.04042.x

Mead, N., \& Bower, P. (2000). Patient-centredness: A conceptual framework and review of the empirical literature. Social science \& medicine, 51(7), 1087-1110. https://doi.org/10.1016/S0277-9536(00)00098-8

Merav, B. N., \& Hochman, O. (2017). Patient-centered care in healthcare and its implementation in nursing. International Journal of Caring Sciences, 10(1), 596-601.

Mirzaei, M., Aspin, C., Essue, B., Jeon, Y.-H., Dugdale, P., Usherwood, T., \& Leeder, S. (2013). A patient-centred approach to health service delivery: Improving health outcomes for people with chronic illness. BMC health services research, 13(1), 251-262.

Moore, L., Britten, N., Lydahl, D., Naldemirci, Ö., Elam, M., \& Wolf, A. (2017). Barriers and facilitators to the implementation of person-centred care in different healthcare contexts. Scandinavian journal of caring sciences, 31(4), 662-673. https://doi.org/10.1111/scs.12376

Naidu, A. (2009). Factors affecting patient satisfaction and healthcare quality. International journal of health care quality assurance, 22(4), 366-381. https://doi.org/10.1108/09526860910964834

National Primary Health Care Development Agency. (2013). Institutionalization of the primary healthcare planning and reviews in Nigeria: Progress and status. Abuja, Nigeria: Federal Government of Nigeria.

Nieboer, A., Lindenberg, S., Boomsma, A., \& Bruggen, A. C. V. (2005). Dimensions of well-being and their measurement: The SPF-IL scale. Social Indicators Research, 73(3), 313-353. https://doi.org/10.1007/s11205-004-0988-2

Nuño, R., Coleman, K., Bengoa, R., \& Sauto, R. (2012). Integrated care for chronic conditions: The contribution of the ICCC Framework. Health Policy, 105(1), 55-64. https://doi.org/10.1016/j.healthpol.2011.10.006

Olakunde, B. O. (2012). Public health care financing in Nigeria: Which way forward? Annals of Nigerian Medicine, 6(1), 4-10. https://doi.org/10.4103/0331-3131.100199

Onge, J. L. S., \& Parnell, R. B. (2015). Patient-centered care and patient safety: A model for nurse educators. Teaching and Learning in Nursing, 10(1), 39-43. https://doi.org/10.1016/j.teln.2014.08.002

Onokerhoraye, A. G., Omuta, G. E., Okonofua, F., Obanovwe, G., Isah, E., Okoro, F., \& Onojeta, F. (2014). Perspectives on Primary Health Care in Nigeria: Past, Present and Future. Benin City, Nigeria: Centre for Population and Environmental Development (CPED).

Pence, M. (1997). Patient-focused models of care. Journal of Obstetric, Gynecologic, \& Neonatal Nursing, 26(3), 320-326.

Peschel, R. E., \& Peschel, E. (1994). Through the Patient's Eyes: Understanding and Promoting Patient-Centered Care. Jama, 271(2), 155-156. https://doi.org/10.1001/jama.1994.03510260087037

Picker Institute. (1987). Principles of patient-centered care. Retrieved 07/06/2019 http://cgp.pickerinstitute.org/?page_id $1 / 41319$

Picker Institute. (1999). Implentation manual. Boston, MA, USA: Picker Institute.

Ponte, P. R., Conlin, G., Conway, J. B., Grant, S., Medeiros, C., Nies, J., . . . Conley, K. (2003). Making patient-centered care come alive: achieving full integration of the patient's perspective. Journal of Nursing Administration, 33(2), 82-90. 
Pulvirenti, M., McMillan, J., \& Lawn, S. (2014). Empowerment, patient centred care and self-management. Health Expectations, 17(3), 303-310. https://doi.org/10.1111/j.1369-7625.2011.00757.x

Rangachari, P., Bhat, A., \& Seol, Y.-H. (2011). Using the “customer service framework" to successfully implement patient-and family-centered care. Quality Management in Healthcare, 20(3), 179-197. 10.1097/QMH.0b013e31822089a3

Rathert, C., Wyrwich, M. D., \& Boren, S. A. (2013). Patient-centered care and outcomes: A systematic review of the literature. Medical Care Research and Review, 70(4), 351-379. https://doi.org/10.1177/1077558712465774

Riding, S., Glendening, N., \& Heaslip, V. (2017). Real world challenges in delivering person-centred care: A community-based case study. British journal of community nursing, 22(8), 391-396. https://doi.org/10.12968/bjcn.2017.22.8.391

Robinson, J. H., Callister, L. C., Berry, J. A., \& Dearing, K. A. (2008). Patient-centered care and adherence: Definitions and applications to improve outcomes. Journal of the American Academy of Nurse Practitioners, 20(12), 600-607. htts://doi.org/10.1111/j.1745-7599.2008.00360.x

Rodriguez-Osorio, C. A., \& Dominguez-Cherit, G. (2008). Medical decision making: Paternalism versus patient-centered (autonomous) care. Current opinion in critical care, 14(6), 708-713. https://doi.org/10.1097/MCC.0b013e328315a611

Rogers, A., Kennedy, A., Nelson, E., \& Robinson, A. (2005). Uncovering the limits of patient-centeredness: implementing a self-management trial for chronic illness. Qualitative Health Research, 15(2), $224-239$. https://doi.org/10.1177/1049732304272048

Rogers, C. R. (1952). “ Client-Centered” Psychotherapy. Scientific American, 187(5), 66-75. https://www.jstor.org/stable/10.2307/24944053

Roumie, C. L., Greevy, R., Wallston, K. A., Elasy, T. A., Kaltenbach, L., Kotter, K., . . Speroff, T. (2011). Patient centered primary care is associated with patient hypertension medication adherence. Journal of behavioral medicine, 34(4), 244-253. 10.1007/s10865-010-9304-6

Saleem, T., J. Alharbi, Olsson, L.-E., Ekman, I., \& Carlström, E. (2014). The impact of organizational culture on the outcome of hospital care: After the implementation of person-centred care. Scandinavian Sournal of Public Health, 42(1), 104-110. https://doi.org/10.1177/1403494813500593

Scholl, I., Zill, J. M., Härter, M., \& Dirmaier, J. (2014). How do health services researchers understand the concept of patient-centeredness? Results from an expert survey. Patient preference and adherence, 8, 1153-1160. https://doi.org/10.2147/PPA.S64051

Shaller, D. (2007). Patient-centered care: What does it take? New York, USA: Commonwealth Fund

Shortell, S. M., Gillies, R. R., Anderson, D. A., Mitchell, J. B., \& Morgan, K. L. (1993). Creating organized delivery systems: The barriers and facilitators. Journal of Healthcare Management, 38(4), 447.

Sidani, S., Collins, L., Harbman, P., MacMillan, K., Reeves, S., Hurlock-Chorostecki, C., \& Soeren, M. (2014). Development of a Measure to Assess Healthcare Providers' Implementation of Patient-Centered Care. Worldviews on Evidence-Based Nursing, 11(4), 248-257. https://doi.org/10.1111/wvn.12047

Smith-Stoner, M. (2011). Teaching patient-centered care during the Silver Hour. The Online Journal of Issues in Nursing, 16(2). https://doi.org/10.3912/OJIN.Vol16No02Man06

Smith, S., Dewar, B., Pullin, S., \& Tocher, R. (2010). Relationship centred outcomes focused on compassionate care for older people within in-patient care settings. International Journal of Older People Nursing, 5(2), 128-136. https://doi.org/10.1111/j.1748-3743.2010.00224.x

Stewart, M. (2013). Patient-Centered Medicine: Transforming the Clinical Method. USA: Taylor \& Francis group.

Stuart, E. H., Jarvis, A., \& Daniel, K. (2008). A ward without walls? District nurses' perceptions of their workload management priorities and job satisfaction. Journal of Clinical Nursing, 17(22), 3012-3020. https://doi.org/10.1111/j.1365-2702.2008.02316.x

Taylor, A., \& Groene, O. (2015). European hospital managers' perceptions of patient-centred care: A qualitative study on implementation and context. Journal of health organization and management, 29(6), 711-728. https://doi.org/10.1108/JHOM-11-2013-0261

Teutsch, C. (2003). Patient-doctor communication. Medical Clinics of North America, 87(5), 1115-1146. 
Theodosius, C. (2013). Emotional labour. In J. M. Gabe, Lee (Ed.), Key concepts in medical sociology (pp. 180). Newcastle, United Kingdom: Sage.

Thompson, R., Heath, H., \& Mills, N. (2013). Dementia: Commitment to the care of people with dementia in hospital settings. London: Royal College of Nursing.

Todres, L., Galvin, K. T., \& Holloway, I. (2009). The humanization of healthcare: A value framework for qualitative research. International Journal of Qualitative Studies on Health and Well-being, 4(2), 68-77. https://doi.org/10.1080/17482620802646204

Toh, S. G., Ang, E., \& Devi, M. K. (2012). Systematic review on the relationship between the nursing shortage and job satisfaction, stress and burnout levels among nurses in oncology/haematology settings. International Journal of Evidence-based Healthcare, 10(2), 126-141. https://doi.org/10.1111/j.1744-1609.2012.00271.x

United Nations Development Programme. (2013). About Nigeria 2016: Updated on June 05, 2013. Retrieved 11/06/2019 http://www.ng.undp.org/content/nigeria/en/home/countryinfo/

V\&VN. (2015). Survey Community health. Netherlands: V\& VN.

Washington, A. E., \& Lipstein, S. H. (2011). The Patient-Centered Outcomes Research Institute-promoting better information, decisions, and health. The New England Journal of Medicine, 365(31). https://doi.org/10.1056/NEJMp1109407

Wensing, M., Grol, R., Weel, C. V., \& Felling, A. (1998). Quality assessment using patients' evaluations of care. The European Journal of General Practice, 4(4), 155-158.

West, E., Barron, D. N., \& Reeves, R. (2005). Overcoming the barriers to patient-centred care: Time, tools and training. Journal of Clinical Nursing, 14(4), 435-443. https://doi.org/10.1111/j.1365-2702.2004.01091.x

Williams, K. F. (2007). Re-examining 'professionalism'in pharmacy: A South African perspective. Social science \& medicine, 64(6), 1285-1296. https://doi.org/10.1016/j.socscimed.2006.11.001

World Health Organisation. (2007). People centred heath care. A policy framework. Geneva: WHO Press.

World Health Organization. (2015). People-centred and integrated health services: An overview of the evidence: Interim report (pp. 1-67). Geneva: WHO.

World Health Organization. (2017). Primary Health Care Systems (PRIMASYS): Case study from Nigeria (pp. 36). Geneva, Switzerland: World Health Organization.

\section{Copyrights}

Copyright for this article is retained by the author(s), with first publication rights granted to the journal.

This is an open-access article distributed under the terms and conditions of the Creative Commons Attribution license (http://creativecommons.org/licenses/by/4.0/). 